\title{
Atividade antimicrobiana de Stevia rebaudiana Bertoni e de adoçantes não calóricos sobre bactérias cariogênicas: estudo in vitro
}

\author{
Antimicrobial activity of Stevia rebaudiana Bertoni and non-caloric \\ sweeteners on cariogenic bacteria: in vitro study
}

\author{
Sandra Liana Henz \\ Rodrigo Alex Arthur* \\ Beatriz Carriconde Colvara*** \\ Raísa Severo ${ }^{* * * *}$ \\ Vinícius Felten ${ }^{* * * *}$
}

\section{Resumo}

Objetivo: avaliar a atividade antimicrobiana in vitro da planta Stevia rebaudiana Bertoni e de adoçantes não calóricos sobre o crescimento de Streptococcus mutans e Lactobacillus casei, micro-organismos cariogênicos presentes na cavidade bucal. Materiais e método: o estudo foi realizado utilizando as cepas padrões de $S$. mutans (UA159) e L. casei (ATCC7469). Foram avaliados diferentes compostos não calóricos substitutos da sacarose nas concentrações de $1 \%, 5 \%$ e $10 \%$ : eritritol (ER), Fit Sucralose ${ }^{\circledR}(\mathrm{SU})$, Stevita ${ }^{\circledR}(\mathrm{ST})$, solução de Stevia rebaudiana Bertoni (SSr) e, como controle positivo, digluconato de clorexidina (DC). A análise do efeito inibitório desses compostos no crescimento das bactérias foi feita por meio da técnica de difusão em ágar. Resultado: observou-se que existe um efeito inibitório de crescimento de ambos os micro-organismos por parte da SSr e do ER, enquanto os demais adoçantes testados não tiveram efeito inibitório sobre esses micro-organismos. Conclusão: os resultados demonstram que SSR e ER apresentam efeito inibidor no crescimento das cepas testadas de $S$. mutans e $L$. casei.

Palavras-chave: Adoçante natural. Cárie dentária. Lactobacillus casei. Stevia. Streptococcus mutans.

\section{Introdução}

A cárie dental caracteriza-se por ser uma doença crônica, que decorre de um processo dinâmico que acontece nos depósitos bacterianos aderidos às superfícies dentárias. A partir de trocas iônicas entre biofilme aderido e superfícies dentárias, ocorrem perdas minerais que podem variar entre condições leves, lesões em estágio subclínico e estágios avançados, podendo resultar na destruição coronária total ${ }^{1}$.

Existem bactérias que têm sido associadas com a etiologia da doença cárie. O Streptococcus mutans, na presença de sacarose, é capaz de produzir um polímero extracelular insolúvel (glucano) que aumenta o potencial cariogênico do biofilme dental. O Lactobacillus casei foi inicialmente considerado um dos principais causadores da doença cárie, porém, verificou-se que ele estava mais associado com a perpetuação da doença, atuando como invasor secundário ${ }^{1}$.

A procura por adoçantes não calóricos aumenta a cada dia em função de maior preocupação mundial com a saúde, uma vez que a alta ingestão de sacarose representa um risco para desenvolvimento de cárie

Doutora em Bioquímica. Professora do Departamento de Odontologia Preventiva e Social da Faculdade de Odontologia da Universidade Federal do Rio Grande do Sul (Ufrgs), Porto Alegre, Rio Grande do Sul, Brasil.

Doutor em Odontologia área de Cariologia. Professor do Departamento de Odontologia Preventiva e Social da Faculdade de Odontologia da Ufrgs, Porto Alegre, Rio Grande do Sul, Brasil.

* Acadêmica da Faculdade de Odontologia da Ufrgs, Porto Alegre, Rio Grande do Sul, Brasil.

Acadêmica da Faculdade de Odontologia da Ufrgs, Porto Alegre, Rio Grande do Sul, Brasil.

Acadêmico da Faculdade de Odontologia da Ufrgs, Porto Alegre, Rio Grande do Sul, Brasil. 
dental, obesidade e diabetes. Em relação à cárie dental, a sacarose desempenha um papel extremamente importante no estabelecimento da doença, pois permite vantagens ecológicas a certas espécies bacterianas do biofilme, tornando-o mais cariogênico ${ }^{2,3}$.

Diversos adoçantes já foram aprovados ou considerados seguros pela Food and Drug Administration (FDA), como a sucralose e o eritritol. Esses adoçantes são considerados não cariogênicos quando utilizados em sua forma isolada ${ }^{4,5}$. No entanto, muitos adoçantes seguros para os dentes, quando associados a outras substâncias, como a lactose, podem se tornar cariogênicos ${ }^{6-8}$.

A sucralose é uma substância não nutritiva, com poder adoçante 600 vezes maior que a sacarose, inerte metabolicamente em muitas cepas orais e mal absorvida no trato gastrointestinal, no entanto, é considerada segura para os dentes e para o consumo humano. Além desse substituto, outros frequentemente utilizados são o eritritol, o xilitol e o sorbitol. O eritritol é considerado um novo poliol (álcool de açúcar), produzido por fermentação em um processo natural ${ }^{5}$. Esse produto tem como principais características: alta estabilidade em ambientes ácidos, alcalinos e quentes; doçura próxima à sacarose; redução calórica, se comparado à sacarose; e, principalmente, não apresenta potencial cariogênico, mostrando exercer um efeito benéfico para a saúde bucal $^{5}$. O xilitol e o sorbitol são comumente usados como substitutos do açúcar, sendo referências como potenciais agentes preventivos da cárie ${ }^{8}$.

Existem relatos de que tanto a sucralose quanto o eritritol apresentam efeitos antimicrobianos. A sucralose mostrou ter efeito antibacteriano contra o periodontopatógeno Aggregatibacter actinomycetemcomitans ${ }^{9}$. Foram observados efeitos anticariogênicos consistentes do eritritol em estudos tanto em animais quanto em humanos ${ }^{10}$. Mäkinen et al. ${ }^{8}$ (2005) conduziram testes in vitro com várias cepas de $S$. mutans utilizando 0,6 M de eritritol, sorbitol, xilitol ou meio não tratado, incubados com o micro-organismo por até 5 horas. $\mathrm{O}$ eritritol inibiu o crescimento de forma mais eficaz em comparação com os outros polióis.

Pesquisas que procuraram alternativas à sacarose resultaram no desenvolvimento de edulcorantes sintéticos. No entanto, além de seus benefícios, estudos em animais provaram que os edulcorantes artificiais causam ganho de peso, tumores cerebrais, câncer e muitos outros riscos para a saúde ${ }^{11}$. Por isso, novas pesquisas são importantes para identificar alimentos naturais e componentes que protejam a cavidade bucal e tragam benefícios para a saúde geral do ser humano.

Os adoçantes naturais à base de esteviosídeo apresentam um valor energético de $0 \mathrm{Kcal} / \mathrm{g}$, já que a maior parte do adoçante ingerido é utilizada por enterobactérias, enquanto que o restante é excretado nas fezes. Além dessa propriedade não calórica, há estudos que comprovam que os adoçantes à base de esteviosídeo não são cariogênicos ${ }^{12,13}$. Gamboa e Chaves $^{12}$ (2012) avaliaram a atividade antibacteriana de extratos de folhas de $S$. rebaudiana contra bactérias cariogênicas. Antes disso, Blauth de Slavutzky $^{14}$ (2010) realizou um estudo in vivo comparando redução de placa dental com bochechos de sacarose e $S$. rebaudiana. Foi demonstrado que $S$. rebaudiana, após o enxágue, reduziu a placa dental, medida pelo índice de Silness-Löe, entre $57 \%$ e $82 \%$, quando comparada com a solução de sacarose ${ }^{14}$.

Outro estudo avaliou o efeito cariogênico de edulcorantes comerciais comparados com a sacarose e a Stevia, utilizando esmalte dental bovino inoculado com cepas padrões de Streptococcus mutans. Observou-se que as amostras contendo Stevia apresentaram menor desenvolvimento de células viáveis, quando comparadas às placas com sacarose. $\mathrm{O}$ estudo encontrou indícios de que a Stevia possui efeito bactericida e que pode alterar de forma negativa o metabolismo bacteriano ${ }^{15}$.

Com o potencial destrutivo da doença cárie, torna-se importante pesquisar meios que auxiliem a prevenir a formação de depósitos bacterianos e que tornem o biofilme menos virulento. Atualmente, a clorexidina é o padrão-ouro em controle do biofilme dental. No entanto, seu uso é restrito, uma vez que é um composto químico que pode apresentar diversos efeitos adversos, como alteração de paladar e manchamento extrínseco das superfícies orais ${ }^{16}$.

Devido aos efeitos deletérios decorrentes do uso da clorexidina, outros compostos têm sido melhor aceitos pela população. Dentre esses produtos, destacam-se os produtos naturais, como a Stevia.

O presente estudo teve como objetivo avaliar a atividade antimicrobiana in vitro de solução de Stevia rebaudiana Bertoni e de solução dos adoçantes eritritol, Stevita ${ }^{\circledR}$ e Fit Sucralose ${ }^{\circledR}$ sobre Streptococcus mutans e Lactobacillus casei. A hipótese nula é de que a Stevia rebaudiana Bertoni e os adoçantes testados não apresentam efeito antimicrobiano sobre $S$. mutans nem sobre L. casei.

\section{Materiais e método}

\section{Preparo das soluções de adoçantes}

Para a realização dos testes, foram preparadas soluções a partir dos seguintes adoçantes: eritritol (Lote: 1254758, Eritritol zerose STD Cargill), Stevita ${ }^{\circledR}$ (Lote: 368005 , ingredientes: lactose, edulcorante natural glicosídeo de esteviol e antiumectante dióxido de silício, Steviafarma Industrial S/A) e Fit Sucralose $®$ (Lote: 489995, ingredientes: lactose, edulcorante artificial sucralose, edulcorante natural glicosídeo de esteviol e antiumectante dióxido de silício, Steviafarma Industrial S/A). Como controle positivo, foram utilizadas soluções de digluconato de clorexidina nas mesmas concentrações das soluções em teste; para controle negativo, água destilada e solução salina. 
As soluções de adoçantes foram preparadas com uma concentração de $25 \%$ e, posteriormente, diluídas em água destilada para obtenção das concentrações finais testadas. Para o preparo da solução de Stevia rebaudiana Bertoni, as folhas secas (Lote: 00143, validade: 06/2017, Vis Vitalis@) foram maceradas, e, após adição de uma quantidade de água destilada, realizou-se um protocolo de duas fervuras intercaladas, com 15 horas de descanso da solução ${ }^{14}$. Todas as soluções foram filtradas utilizando-se membrana 0,22 $\mu \mathrm{M}$.

\section{Inócullo}

Os micro-organismos utilizados foram as cepas de Streptococcus mutans UA159 e de Lactobacillus casei ATCC 7469, para testar a ação dos diferentes compostos.

As cepas de $S$. mutans e de $L$. casei foram reativadas a partir de estoques congelados em placas contendo meio ágar triptona de soja (TSA) e incubadas por 48 horas, a $37^{\circ} \mathrm{C}$, em microaerofilia. Após, as colônias crescidas foram coletadas e inoculadas em frasco contendo meio caldo triptona de soja (TSB), suplementado com $0,5 \%$ de sacarose, e incubadas a $37^{\circ} \mathrm{C}$ durante 24 horas, em microaerofilia. Uma alíquota de $2 \mathrm{ml}$ foi transferida para um novo frasco contendo TSB e incubada nas mesmas condições. Após 24 horas, realizou-se o ajuste da densidade óptica (DO) para 5, na escala Mc Farland, em ambas as suspensões dos micro-organismos.

\section{Teste difusão em ágar}

Foram testadas as concentrações de 1\%, 5\% e $10 \%$ das soluções de adoçantes e da solução de Stevia em triplicata. Inicialmente, foi inoculado $200 \mu \mathrm{L}$ da suspensão bacteriana com DO ajustada ( $S$. $m u$ tans ou $L$. casei) em placas de Petri contendo meio TSA e espalhada na superfície com auxílio de pérolas de vidro estéreis. Após disposição do inóculo, três cilindros plásticos estéreis foram dispostos em cada placa de maneira equidistante, e no interior desses cilindros foram adicionados $50 \mu \mathrm{L}$ da solução correspondente, sendo uma placa para cada concentração testada. Os cilindros foram removidos da superfície do ágar após duas horas, e as placas foram incubadas a $37^{\circ} \mathrm{C}$ em microaerofilia.

A medição dos halos de inibição foi realizada após 48 horas de incubação com auxílio de uma régua, de modo que os resultados foram registrados em milímetros. As análises foram realizadas no Laboratório de Bioquímica e Microbiologia Bucais da Faculdade de Odontologia da Universidade Federal do Rio Grande do Sul.

\section{Análise estatística}

Todos os resultados obtidos foram expressos utilizando o valor das medianas das repetições em milímetros e quartis. Os resultados de halo de inibição em cada uma das condições testadas foram individualmente comparados para $S$. mutans e L. casei. Os dados foram estatisticamente comparados entre diferentes produtos/concentrações por Kruskal-Wallis, por teste de Student-Newman-Keuls. O nível de significância foi estabelecido como $5 \%$, e as análises foram realizadas no software SigmaPlot 12.0.

\section{Resultados}

Não foram observados halos de inibição na presença de água ou de solução salina tanto em relação ao $S$. mutans quanto ao $L$. casei.

Em relação ao $S$. mutans, halos de inibição estatisticamente maiores foram encontrados na presença de clorexidina em relação a eritritol e Stevia, independentemente das concentrações analisadas. Além disso, não foi encontrada diferença estatística no tamanho do halo de inibição entre as concentrações $1 \%, 5 \%$ e $10 \%$ para clorexidina, eritritol e Stevia. Não foram observados halos de inibição para os produtos sucralose e Stevita em nenhuma das concentrações analisadas.

Em relação ao L. casei, halos de inibição estatisticamente maiores foram encontrados na presença de clorexidina em relação à Stevia, nas concentrações de $1 \%$ e $5 \%$, e em relação ao eritritol, em $1 \%$. Além disso, não foi encontrada diferença estatística no tamanho do halo de inibição entre as concentrações $1 \%, 5 \%$ e $10 \%$ para clorexidina. Não foram observados halos de inibição para os produtos Stevia em $10 \%$ e eritritol em $5 \%$ e $10 \%$. Ainda, não foram observados halos de inibição para os produtos sucralose e Stevita nas concentrações analisadas.

Tabela 1 - Halos de inibição (mediana; [1ำ quartil; 3ำ quartil]; mm) para os micro-organismos $S$. mutans e $L$. casei em relação aos produtos analisados

\begin{tabular}{|c|c|c|}
\hline \multirow{2}{*}{ Produtos } & \multicolumn{2}{|c|}{ Micro-organismo } \\
\hline & S. mutans & L. casei \\
\hline Stevia 1\% & $14,5[14,0 ; 15,0] \mathrm{b}$ & $12,0[12,0 ; 13,0]$ bc \\
\hline Stevia 5\% & $17,0[16,0 ; 17,0] \mathrm{b}$ & $16,0[12,0 ; 17,0]$ bc \\
\hline Stevia 10\% & $18,0[17,0 ; 19,0] \mathrm{b}$ & $0,0[0,0 ; 0,0] \mathrm{c}$ \\
\hline Eritritol $1 \%$ & $17,5[15,0 ; 20,0] \mathrm{b}$ & $19,0[15,0 ; 19,0]$ bc \\
\hline Eritritol 5\% & $15,0[12,0 ; 15,0] \mathrm{b}$ & $0,0[0,0 ; 0,0] \mathrm{c}$ \\
\hline Eritritol 10\% & $15,0[11,0 ; 19,0] \mathrm{b}$ & $0,0[0,0 ; 0,0] \mathrm{c}$ \\
\hline Sucralose $1 \%$ & $0,0[0,0 ; 0,0] \mathrm{c}$ & $0,0[0,0 ; 0,0] \mathrm{c}$ \\
\hline Sucralose $5 \%$ & $0,0[0,0 ; 0,0] \mathrm{c}$ & $0,0[0,0 ; 0,0] \mathrm{c}$ \\
\hline Sucralose $10 \%$ & $0,0[0,0 ; 0,0] \mathrm{c}$ & $0,0[0,0 ; 0,0] \mathrm{c}$ \\
\hline Stevita $1 \%$ & $0,0[0,0 ; 0,0] \mathrm{c}$ & $0,0[0,0 ; 0,0] \mathrm{c}$ \\
\hline Stevita 5\% & $0,0[0,0 ; 0,0] \mathrm{c}$ & $0,0[0,0 ; 0,0] \mathrm{c}$ \\
\hline Stevita $10 \%$ & $0,0[0,0 ; 0,0]$ c & $0,0[0,0 ; 0,0] \mathrm{c}$ \\
\hline Clorexidina $1 \%$ & $30,0[28,0 ; 32,0]$ a & $27,0[26,0 ; 30,0]$ a \\
\hline Clorexidina 5\% & $31,0[28,0 ; 33,0] \mathrm{a}$ & $29,0[29,0 ; 30,0]$ a \\
\hline Clorexidina $10 \%$ & $30,0[29,0 ; 30,0] \mathrm{a}$ & $26,0[25,0 ; 27,0]$ a \\
\hline
\end{tabular}

Fonte: elaboração dos autores. 


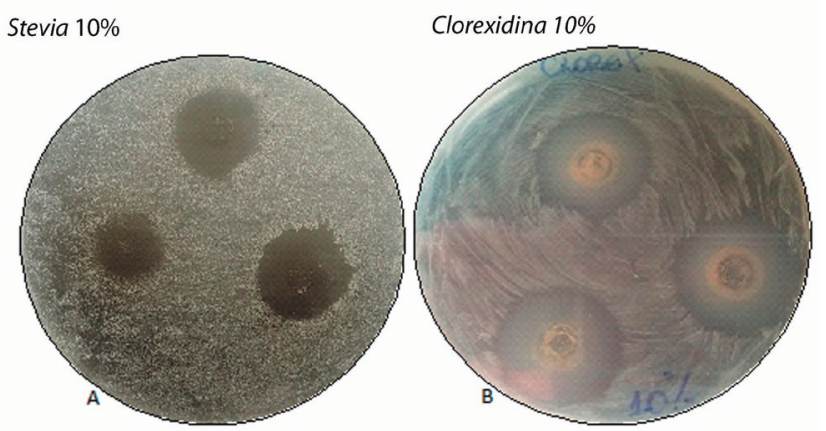

Figura 1 - Halos de inibição formados pela solução de Stevia rebaudiana Bertoni na concentração de $10 \%$ com a cepa S. mutans UA159 (A) - Halos de inibição formados pela solução de clorexidina na concentração de $10 \%$ com a cepa $S$. mutans UA159 (B)

Fonte: elaboração dos autores.

\section{Discussão}

O estudo teve como objetivo avaliar a atividade antimicrobiana in vitro de solução da planta Stevia rebaudiaña Bertoni e dos adoçantes não calóricos ${ }_{\mathrm{B}}$ eritritol, Stevita ${ }^{\circledR}$ e Fit Sucralose ${ }^{\circledR}$.

Os resultados encontrados mostram que a solução da planta Stevia rebaudiana Bertoni apresenta inibição sobre o crescimento bacteriano dos micro-organismos Streptococcus mutans e Lactobacillus casei, o que coincide com resultados encontrados na literatura, como em estudo realizado com adoçantes xilitol, sorbitol e esteviosídeo, em que se constatou que não houve crescimento de $S$. mutans em meios contendo esses adoçantes ${ }^{17}$. Outro estudo demonstrou que o esteviosídeo não é metabolizado pelo $S$. mutans como fonte de carbono, bem como não permite a formação de ácidos e síntese de polissacarídeos extracelulares ${ }^{18}$. Em outro estudo, os adoçantes esteviosídeo, aspartame, xilitol e sacarina não foram metabolizados por micro-organismos, em especial por S. mutans. Já o extrato da folha de Stevia rebaudiana foi um potente inibidor da síntese de polissacarídeo insolúvel, o qual desempenha importante papel na formação do biofilme dental ${ }^{19,20}$.

Em relação ao eritritol, os resultados encontrados coincidem com o que vem sendo demonstrado em relação ao potencial dessa substância como inibidora do crescimento microbiano, como o avaliado em estudo in vivo que constatou redução nos níveis de $S$. mutans na placa e na saliva de indivíduos que foram expostos aos polióis eritritol e xilitol ${ }^{8,21}$. Outro estudo mostrou que o eritritol diminuiu a abundância de Porphyromonas gingivalis e Streptococcus gordonii, quando cultivados conjuntamente ${ }^{22}$.

Um potencial efeito antimicrobiano e, consequentemente, anticariogênico tem sido descrito para a sucralose ${ }^{15,23}$. Estudo in situ demonstrou menor desmineralização do esmalte por adoçantes comerciais que continham Stevia, sucralose, sacarina e aspartame, quando foram comparados à desmineralização obtida com exposição à sacarose. Contudo, a falta de resultados inibitórios sobre o crescimento bacteriano no uso dos adoçantes Fit Sucralose ${ }^{\circledR}$ e Stevita ${ }^{\circledR}$ no presente estudo demonstra a interferência causada pela combinação de diferentes substâncias na composição dos adoçantes, o que faz com que não haja mais um controle da concentração de sucralose e Stevia que está sendo aplicada sobre as bactérias, uma vez que ambos adoçantes apresentam como ingrediente em maior quantidade a lacto$\mathrm{se}^{6}$. Estudos demonstram que adoçantes como a sucralose não são cariogênicos por si só, mas, quando em associação com ingredientes que conferem volume, como a lactose, esses adoçantes podem não ser mais seguros para os dentes. Isso porque a lactose é um carboidrato fermentável pelas bactérias orais e que ocasiona quedas de $\mathrm{pH}$ críticas principalmente para a dentina ${ }^{6-8}$.

$\mathrm{O}$ uso de um controle positivo de digluconato de clorexidina nas mesmas concentrações que as demais substâncias testadas (1\%, $5 \%$ e $10 \%)$ é importante, uma vez que essa substância é considerada o padrão-ouro no controle químico do biofilme dental, sendo esperado um efeito inibitório do crescimento bacteriano, e essa substância corriqueiramente é utilizada como controle em estudos in vitro ${ }^{22,23}$.

A substituição parcial de açúcar refinado da dieta é uma importante ferramenta na prevenção da cárie dentária. A capacidade desses adoçantes de não serem metabolizados por bactérias relacionadas com a etiologia da cárie e o potencial inibitório do crescimento bacteriano fazem dos substitutos do açúcar estratégicos para a promoção da saúde. Outros estudos, in situ e in vivo, serão delineados para avaliar a ação das soluções de Stevia e de eritritol sobre a arquitetura e a composição do biofilme dentário, já que, quando se busca um produto que interfira na formação do biofilme, não se restringe $o$ pensamento apenas à cárie dental, pois, como o biofilme dentário se torna menos virulento e mais fácil de ser controlado, tem-se um efeito benéfico sobre a saúde bucal como um todo.

\section{Conclusão}

Os resultados demonstram que as soluções de Stevia rebaudiana Bertoni e eritritol apresentam um efeito inibidor no crescimento de Streptococcus mutans e Lactobacillus casei, evidenciando um potencial emprego dessas substâncias para modificar a cariogenicidade do biofilme. Estudos adicionais são necessários para melhor identificar o mecanismo responsável pela inibição do crescimento desses micro-organismos e também para avaliar a efetividade dessas soluções quando utilizadas in vivo. 


\section{Abstract}

Objective: The study evaluated the in vitro antimicrobial activity of the Stevia rebaudiana Bertoni plant and non-caloric sweeteners on the growth of Streptococcus mutans and Lactobacillus casei, which are cariogenic microorganisms present in the oral cavity. Materials and method: The study was conducted using the standard strains of S. mutans (UA159) and L. casei (ATCC7469). Different non-caloric compounds were evaluated at concentrations of $1 \%, 5 \%$, and 10\%: erythritol (ER), Fit Sucralose ${ }^{T M}(\mathrm{SU})$, Stevita $^{\mathrm{TM}}$ (ST), Stevia rebaudiana Bertoni solution ( $\mathrm{SSr}$ ), and chlorhexidine digluconate (CD) as positive control. The inhibitory effect of these compounds on the growth of bacteria were analyzed by the agar diffusion technique. Result: There was a growth inhibition effect for both microorganisms by SSr and ER, whereas the other sweeteners tested had no inhibitory effect on the microorganisms. Conclusion: The results showed that SSr and ER present an inhibitory effect on the growth the strains tested of $S$. mutans and $L$. casei.

Keywords: Natural sweetener. Dental caries. Lactobacillus casei. Stevia. Streptococcus mutans.

\section{Referências}

1. Maltz MT. Cariologia. In: Toledo OA. Odontopediatria: fundamentos para a prática clínica. 2. ed. São Paulo: Premier; 1996. p. $105-33$.

2. Torres CRG, Kubo CH, Anido AA, Rodrigues JR. Agente antimicrobianos e seu potencial de uso na odontologia. Rev Fac Odontol Sao Jose Campos 2000; 3(2):43-52.

3. Rölla G. Why is sucrose so cariogenic? The role of glucosyltransferase and polysaccharides. Scand J Dent Res 1989; 97(2):115-9.

4. Mäkinen KK. Sugar alcohol sweeteners as alternatives to sugar with special consideration of xylitol. Med Princ Pract 2011; 20(4):303-20.

5. de Cock P. Erythritol sweeteners and sugar alternatives in food technology. Hoboken: Wiley-Blackwell; 2012. pp. 213-241.

6. Aires CP, Tabchoury CPM, Del Bel Cury AA, Cury JA. Effects of a lactose-containing sweetener on root dentin demineralization in situ. Caries Rev 2002; 36:167-9.

7. Kawanabe J, Hirasawa M, Takeuchi T, Oda T, Ikeda T. Noncariogenicity of erythritol as a substrate. Caries Res 1992; 26(5):358-62

8. Mäkinen KK, Saag M, Isotupa KP, Olak J, Nõmmela R, Söderling E, et al. Similarity of the effects of erythritol an xylitol on some risk factors of dental caries. Caries Res 2005; 39(3):207-15

9. Prashant GM, Patil RB, Nagaraj T. The antimicrobial activity of the three commercially available intense sweeteners against common periodontal pathogens: an in vitro study. $\mathrm{J}$ Contemp Dent Pract 2012; 1;13(6):749-52.

10. Honkala S, Runnel R, Saag M, Olak J, Nõmmela R, Russak $\mathrm{S}$, et al. Effect of erythritol and xylitol on dental caries prevention in children. Caries Res 2014; 48(5):482-90.

11. Gupta P, Gupta N, Pawar AP, Birajdar SS, Natt AS, Singh HP. Role of sugar and sugar substitutes in dental caries: a review. ISRN Dentistry Dec 29; 2013:519421.
12. Gamboa F, Chaves M. Antimicrobial potential of extracts from Stevia rebaudiana leaves against bacteria of importance in dental caries. Acta Odontol Latinoam 2012; 25(2):171-5.

13. Ruiz JCG, Ordoñez YBM, Campos MRS. Biological activity of Stevia rebaudiana Bertoni and their relationship to health. Food Science and Nutrition 2015; [acesso em $1^{\circ} \mathrm{dez}$. 2015]. Disponível em URL: http://www.tandfonline.com/doi/ full/10.1080/10408398.2015.1072083.

14. Slavutzky SMB. Stevia and sucrose effect on plaque formation. J Verb Lebensm 2010; 5(2):213-6.

15. Giacaman RA, Campos P, Muñoz-Sandoval C, Castro RJ. Cariogenic potential of commercial sweeteners in an experimental biofilm caries model on enamel. Arch Oral Biol 2013; 58(9):1116-22.

16. Matsukubo T, Takazoe I. Sucrose substitutes and their role in caries prevention. Int Dent J 2006; 56(3):119-30.

17. Yabu M, Takase M, Toda K, Tanimoto K, Yasutake A. Studies on stevioside, natural sweetener. Effect on the growth of some oral microorganisms. Hiroshima DaigakuShigakuZasshi 1977; 9(1):12-7.

18. Ikeda T, Okada A, Motada R. Effects of stevioside on certain metabolism of Streptococcus mutans. J Nihon Univ Sch Dent 1978; 4:24-7.

19. Chedid SJ. Efeitos dos adoçantes: steviosideo, aspartame, xilitol e sacarina sobre a fermentação e síntese de polissacarídeos extracelulares insolúveis pelo Streptococcus mutans G55 E LM7 e pela placa dentária in vitro [Dissertação de Mestrado]. São Paulo: Faculdade de Odontologia da Universidade de São Paulo; 1990

20. Pinheiro CE, Oliveira SS, Silva MSMB, Poletto MIF, Pinheiro CF. Efeito dos extratos de guaraná e de Stévia Rebaudiana Bertoni (folhas) e do esteviosideo, sobre a fermentação e a síntese de polissacarídeos extracelulares insolúveis da placa dentária. Rev Odontol USP 1987; 1(4):9-13.

21. Runnel R, Mäkinen KK, Honkala S, Olak J, Mäkinen PL, Nõmmela R, et al. Effect of three-year consumption of erythritol, xylitol and sorbitol candies on various plaque and salivary caries-related variables. J Dent 2013; 41(12):1236-44.

22. Hashino E, Kuboniwa M, Alghamdi AS, Yamaguchi M, Yamamoto R, Cho H, et al. Erythritol alters microstructure and metabolomic profiles of biofilm composed of Streptococcus gordonii and Porphyromonasgingivalis. Mol Oral Microbiol 2013; 28(6):435-51.

23. Ferrazzano GF, Cantile T, Alcidi B, Coda M, Ingenito A, Zarrelli A, et al. Is Stevia rebaudiana Bertoni a non cariogenic sweetener? A review. Molecules 2015; 21(1):E38.

\section{Endereço para correspondência:}

Sandra Liana Henz

Faculdade de Odontologia, Universidade Federal do Rio Grande do Sul

Rua Ramiro Barcelos, 2.492

90035-003, Porto Alegre, RS, Brasil

Telefone: (51) 999750010

E-mail: slhenz@yahoo.com.br

Recebido: 09/01/18. Aceito: 20/02/18. 